\title{
UMA EXPERIÊNCIA DIDÁTICA ATRAVÉS DA FERRAMENTA STOP MOTION PARA O ENSINO DE MODELOS ATÔMICOS
}

\author{
T. A. CORRÊA ${ }^{1}$, H. L. MARTINS ${ }^{2}$, R. N. MILLAN ${ }^{3}$, A. C. MARANGONI ${ }^{4}$ \\ Universidade do Estado de Minas Gerais \\ ORCID ID: https://orcid.org/0000-0001-9936-1479 ${ }^{1}$ \\ tais.correa@uemg.br
}

Submetido 28/04/2020 - Aceito 01/07/2020

DOI: $10.15628 /$ holos.2020.9986

\section{RESUMO}

A sociedade contemporânea vivencia evoluções culturais e tecnológicas nas quais as instituições de ensino e os pesquisadores têm buscado adequação e instrumentalização frente as suas demandas. Neste sentido as Tecnologias de Informação e Comunicação (TICS) aliadas ao lúdico, apresentam-se como uma ferramenta pedagógica atrativa e favorável para a construção de conhecimento como, por exemplo, para conceitos teóricos e abstratos dentro da disciplina de química. Neste contexto, o presente trabalho teve como objetivo trabalhar a Técnica Cinematográfica Stop Motion com alunos do ensino médio, como recurso audiovisual e instrumento pedagógico, abordando o conteúdo didático "Evolução dos Modelos Atômicos". O trabalho resultou na produção de 6 (seis) micrometragens de animação que permitiram a síntese dos conceitos, reflexão sobre conteúdos explorados, a interação do estudante com a ciência de forma lúdica, além da efetivação de uma importante ferramenta no processo de construção do conhecimento e sua consequente aplicação de forma prática.

PALAVRAS-CHAVE: Stop Motion, Ensino de Química, Animação, TICs

\section{A TEACHING EXPERIENCE THROUGH THE STOP MOTION TOOL FOR TEACHING ATOMIC MODELS}

\begin{abstract}
Contemporary society is experiencing cultural and technological developments, in which educational institutions and researchers have sought to adapt and instrumentalize in face of their demands. Thereby, Information and Communication Technologies (ICT) combined with ludic, present as an attractive and favorable pedagogical tool to the construction of knowledge, for example, for theoretical and abstract concepts within the discipline of chemistry. We work with
\end{abstract}

high school students using Stop Motion Cinematographic Technique, as an audiovisual resource and pedagogical instrument, to understand the evolution of atomic Models. This work resulted in the production of 6 (six) animated films that allowed the synthesis of concepts, reflection on explored contents, interaction of the students with science in a playful way, in addition to the implementation of an important tool in the process of knowledge construction in a practical way.

KEYWORDS: Stop Motion, Chemistry teaching, Animation, ICT.

HOLOS, Ano 36, v.6, e9986, 2020 


\section{INTRODUÇÃO}

As disciplinas de Química, Física, Biologia e Matemática são componentes curriculares do Ensino Médio (2008) e integram a área de conhecimento "Ciências da Natureza, Matemática e suas Tecnologias", conforme previsto nos Parâmetros Curriculares Nacionais (PCN). A investigação sobre a natureza e o desenvolvimento tecnológico são eixos comuns das ciências que compõe a área, os quais compartilham linguagens para a representação e sistematização do conhecimento de fenômenos ou dos processos naturais e tecnológicos, além de uma inter-relação dinâmica de conceitos cotidianos e científicos diversificados (Brasil, 2008; Paz et al., 2010).

Entretanto, proporcionar aulas próximas do cotidiano dos alunos e compreender alguns temas na ciência, dentre eles conceitos e teorias abstratas da química, continua sendo difícil para a maioria dos estudantes, tendo em vista que nem sempre esse conhecimento é transmitido com a didática adequada para que o aluno possa entender a sua relação com a vida e elaborar ideias de forma significativa. Diante do exposto, os professores têm em mãos mais um desafio: diversificar suas aulas, ressaltar a importância do ensino de ciências e intensificar o processo ensinoaprendizagem, tornando-as motivadoras e contextualizadas com o cotidiano dos alunos.

Nessa premissa, o ensino de ciências é atualmente objeto de pesquisas que avaliam as práticas pedagógicas que auxiliam no processo ensino-aprendizagem, além de mensurar sua importância na vida pessoal e profissional do estudante (Melo, Campos \& Almeida, 2015; Nicola \& Paniz, 2016; Meneses \& Nuñes, 2018; Seixas, Calabró \& Sousa, 2017). O objetivo é promover aumento na qualidade do ensino, tornar o espaço escolar agradável e atraente para os alunos por meio de modelos, ilustrações, jogos educacionais, experimentação e Tecnologias de Informação e Comunicação (TICs) (Paula, Paula \& Henrique, 2017; Reis et al., 2013; Santos et al., 2015).

De acordo com Martins et al. (2018) ainda é observável a discordância entre o modo de ensino-aprendizado atual e o perfil dos estudantes do século XXI, necessitando modernização e mudanças na aplicação de práticas pedagógicas, de tal forma que o sistema de ensinoaprendizagem deixe de ser estruturado com ferramentas e metodologias descompassadas em analogia ao perfil dos estudantes pertencentes ao novo século, cada vez mais conectados e familiarizados com as tecnologias.

Souza e Tolentino-Neto (2018) apontam que o ensino de ciências pautado na perspectiva da interação entre Ciência, Tecnologia e Sociedade (CTS), mostra-se pertinente e enriquecedor, contribuindo para a formação de cidadãos aptos a participar da tomada de decisão frente aos problemas inerentes a sociedade na qual estão inseridos, dando destaque as TICs, elementos importantes da sociedade atual.

As TICs vêm promovendo mudanças sociais e educacionais e são apresentadas aos professores propostas diversificadas para construção de uma educação mais atrativa, apreciável, contextualizada e conveniente à construção de novos conhecimentos (Comazzetto et al., 2016). A inserção de ferramentas tecnológicas dentro do contexto educacional sejam elas, presenciais e/ou 
virtuais, podem facilitar a interação e troca de informações entre professor e aluno. Neste cenário, o papel do professor é modificado, deixando de ser o único detentor do saber para tornar-se um gestor da aprendizagem, ensinando os discentes a aprender, pesquisar e a trocar informações. Ainda, o professor necessita despertar o espírito crítico, diante do número imenso de informações que circulam nas redes, promover educação visando a autonomia e as exigências do mundo contemporâneo, que demanda um papel ativo dos estudantes em seu processo de aprendizagem (Costa \& Souza, 2017; Silva, 2016).

Os recursos audiovisuais mostram-se como alternativa atual e amplamente empregada dentro da perspectiva das TIC's, principalmente como ferramenta didática em sala de aula, podendo ser utilizados e desenvolvidos por meio de smartphones, tablets, computadores, etc. A aplicação de atividades e/ou materiais pedagógicos que utilizam imagens e sons facilita a demonstração de conteúdos e suas peculiaridades, ampliando o tema, sendo também considerado um mobilizador de aspecto emocional.

Nesse contexto, diferentes propostas de atividades podem ser desenvolvidas em sala de aula, dentre elas estão: produções de vídeos de curtas-metragens, animações e documentários, elaborados através de smartphones, câmeras digitais de fotografia ou qualquer tecnologia que possua em sua estrutura uma câmera filmadora (Marangoni et al., 2017).

A filmagem em Stop Motion é uma técnica de animação que remonta aos primórdios do cinema, despertando a atenção e curiosidade de seus espectadores. Esse recurso audiovisual pode ser usado para a produção de filmes de micrometragens, fotografando-se objetos/imagens quadro a quadro, em um valioso trabalho de imaginação e criatividade. Os autores Paula, Paula e Henrique (2017), ainda complementam que a técnica Stop Motion:

[...] demanda um trabalho artesanal rico em minúcias que pressupõem mais investimento de tempo e criatividade de seus mentores e executores do que com o uso de recursos tecnológicos de ponta. Além disso, com qualquer câmera fotográfica e um simples editor de vídeo no computador já se pode dar início à produção de uma animação. Tendo esses recursos em mãos, concebe-se a ideia, planeja-se o roteiro, selecionam-se os materiais necessários para construção das cenas a serem fotografadas, capturam-se as imagens, lançam-se as imagens no editor de vídeo, realizam-se os ajustes, incluem-se os efeitos (músicas, legendas, entre outros), define-se a velocidade de apresentação das imagens e a animação está feita (Paula, Paula \& Henrique, 2017, p. 146)

As potencialidades no uso de Stop Motion no ensino das disciplinas que compõem a área de conhecimento "Ciências da Natureza, Matemática e suas Tecnologias" são relatadas em outros trabalhos. Rodrigues e Lavino (2020) consideram a técnica como um aparato de baixo custo para produção de animações como ferramenta didática no ensino da Física; Martins, Galego e Araújo (2017) discutem a contribuição da produção de materiais audiovisuais como importante recurso didático no ensino de Biologia e Rodrigues (2019) ressalta a importância das mídias digitais no processo educacional, num sentido amplo, como metodologia de ensino.

A utilização da técnica Stop Motion pode ser uma aliada no processo ensino-aprendizagem, considerando que o aluno estará envolvido de forma participativa na construção do conhecimento, proporcionando ambiente agradável e lúdico para o aprendizado, e a interação do aluno com a 
ciência. Diante do exposto, o presente trabalho objetivou utilizar esta técnica com estudantes do ensino médio, como instrumento pedagógico para o ensino de química, por meio da produção de micrometragens de animação, abordando o conteúdo "Evolução dos Modelos Atômicos" e relatar os resultados da experiência da atividade proposta.

\section{METODOLOGIA}

O trabalho se refere a um estudo de caso de cunho interpretativo, desenvolvido com estudantes do $2 \circ$ ano do ensino médio regular de uma escola estadual. $O$ trabalho foi realizado no ano de 2018, nas dependências da Escola Estadual Vicente Macedo e da Universidade do Estado de Minas Gerais, ambos localizados no município de Frutal, Minas Gerais.

O estudo foi estruturado em cinco etapas: (i) Apresentação da técnica cinematográfica Stop Motion aos estudantes através da apresentação de um filme pré-selecionado e discussão sobre sua trajetória até os tempos atuais; (ii) Oficina sobre a técnica Stop Motion; (iii) Encontros para a construção do material a ser apresentado, (iv) Socialização dos vídeos produzidos e (v) aplicação de questionário estruturado (Quadro 1) aos participantes através do aplicativo Google forms, respondido individualmente.

Quadro 1: Perguntas do questionário aplicado aos estudantes.

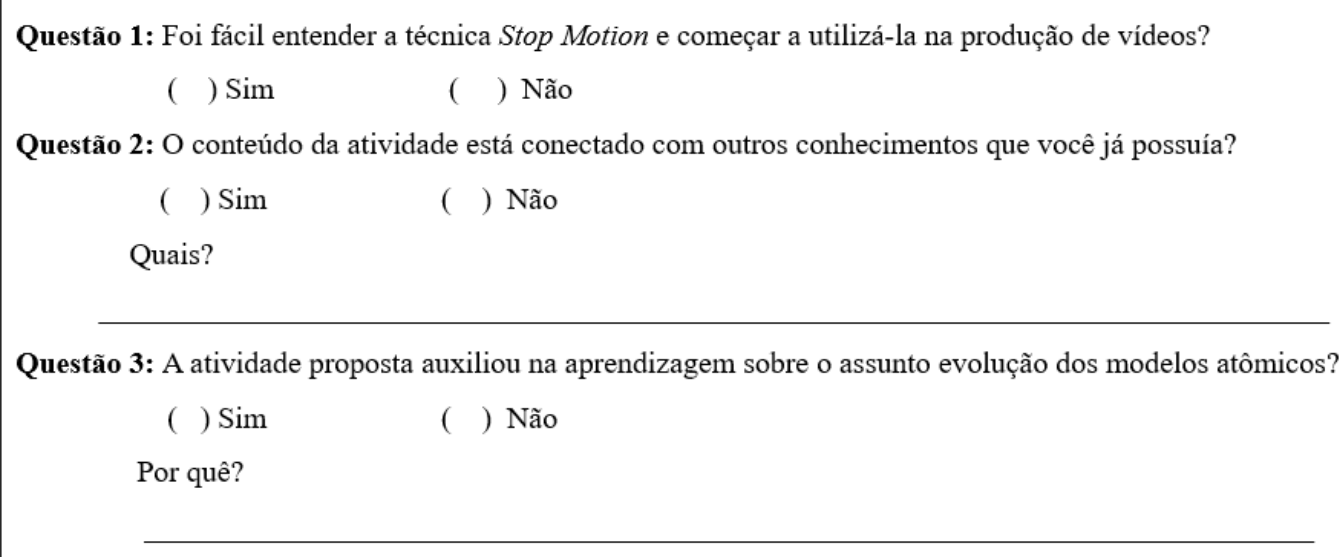

Na oficina sobre Stop Motion foram abordadas duas temáticas simultaneamente: o conteúdo de Química Geral a ser trabalhado através do tópico "Evolução de Modelos atômicos" presente no Conteúdo Básico Comum de Química para o Ensino Médio (Brasil, 2008) e as etapas da produção das micrometragens apresentando técnicas de fotografia, roteirização e edição de áudio e vídeo com o software livre Microsoft Movie Maker (disponível em: http://windows.microsoft.com/pt-br/windows/movie-maker, acesso em 28/08/2018), instalado nos computadores da escola e da universidade, visando a produção do material audiovisual.

As reuniões em grupo para construção dos vídeos foram realizadas fora dos horários regulares de aula, com o acompanhamento dos pesquisadores. Nesta ação foram disponibilizados: material didático abordando um breve histórico sobre a "Evolução dos Modelos Atômicos", a 
biografia dos cientistas e roteiro para estruturação do vídeo, delineando as etapas da atividade, dentre elas o título, a sinopse, o nome da equipe, o roteiro (cena, texto, diálogo) e os materiais utilizados.

Os estudantes foram divididos em grupos de 5 ou 6 componentes que trabalharam os conteúdos: teoria atômica de Dalton, modelo atômico de Rutherford, modelo atômico de Bohr e o modelo de subníveis de energia. Em seguida, os grupos elaboraram os roteiros descrevendo como seria a produção do material audiovisual. Os discentes também receberam embasamento teórico sobre a técnica Stop Motion e materiais de apoio, tais como: massa de modelar, canetas hidrográficas, giz de cera, folhas de papel A4 e computadores.

\section{RESULTADOS E DISCUSSÃO}

A atividade proposta contou com a participação inicial de 38 alunos com idade entre 16 e 18 anos, do total de 42 alunos matriculados em duas turmas do 20 ano do ensino médio, correspondendo assim a $90 \%$ de participação discente. Ambas as turmas funcionavam em período diurno na E. E. Vicente Macedo, localizada no município de Frutal-MG, Triângulo Mineiro.

Um exemplo da utilização da técnica cinematográfica Stop Motion foi apresentado aos alunos através da exibição de um pequeno trecho do filme STAR WARS. A ação auxiliou na abordagem pretendida junto aos estudantes, fato observado através dos questionamentos em sala de aula sobre a ferramenta empregada na produção da animação. A apresentação do recurso audiovisual auxiliou no despertar do interesse dos participantes sobre a técnica além de ter proporcionado um momento de interatividade e descontração.

A ação seguinte contou com o desenvolvimento da oficina de Stop Motion. Como estratégia prática foi proposta aos alunos a elaboração, em sala de aula, de um flipbook (livro mágico), que através da sobreposição de vários desenhos semelhantes, colocados em sequência e folheados rapidamente, criavam a ilusão do movimento do personagem. Em seguida, os desenhos foram fotografados individualmente utilizando a câmera fotográfica do celular dos estudantes e as imagens foram importadas para o programa Microsoft Movie Maker, onde cada imagem tornou-se um quadro (frame). Ajustou-se o tempo de transição entre os quadros, criando assim um vídeo de curta duração (máximo de 15 segundos) com o material produzido naquele momento. Em seguida os alunos aprenderam a inserir a trilha sonora e efeitos, adaptando-os ao tempo de exibição da animação. O desenvolvimento da oficina (Figura 1) despertou o entusiasmo dos estudantes pela atividade, ao dar movimento/vida a um objeto inanimado, abordando de forma didática, lúdica e interativa a produção dos vídeos. 

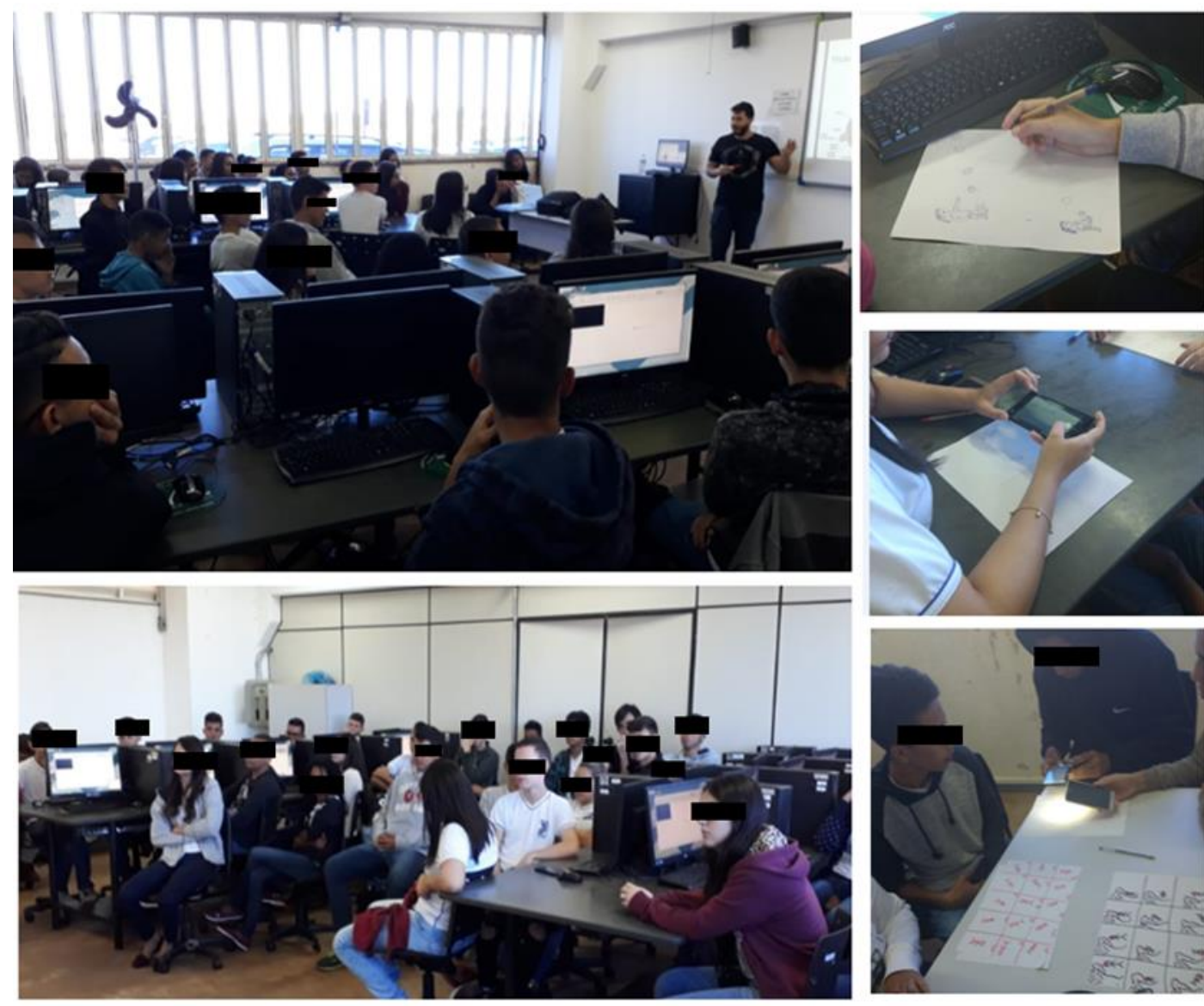

Figura 1: Oficina sobre Stop Motion.

Na sequência, foram realizados encontros com os grupos de trabalho para apropriação do conhecimento já produzido em relação ao tema abordado e a ser representado em uma animação por eles elaborada. Esses encontros foram momentos de revisão do conteúdo de química, valorizando a reflexão e o diálogo sobre os fenômenos envolvidos nas descobertas científicas, com a construção do conhecimento de forma participativa e efetiva entre os estudantes. Vale ressaltar que, durante o desenvolvimento das atividades, o professor exerceu importante e desafiadora função de instigar, orientar e ajudar o aluno na construção do conhecimento, corroborando assim com Souza e Souza (2018), que abordam a dificuldade do docente e da falta de incentivo na inovação nos métodos educacionais que, quando aplicada, transforma alunos e professores, mostrando a capacidade de todos se tornarem protagonistas no ensino-aprendizagem.

Os alunos ilustraram as descobertas científicas sobre os modelos atômicos de Dalton, Thompson, Rutherford e Bohr através da criação dos quadros usando os materiais disponibilizados (massa de modelar, folhas A4, canetas hidrográficas e giz de cera) (Figura 2). As tarefas como elaboração do roteiro, modelagem e/ou desenho dos bonecos/cenários e escolha da trilha sonora foram divididas de acordo com a aptidão dos componentes do grupo, dando início a construção dos vídeos. Durante o processo de elaboração das micrometragens de animação, os alunos criaram um grupo de discussão através do aplicativo de mensagens WhatsApp, propiciando ambiente de troca de informações. 

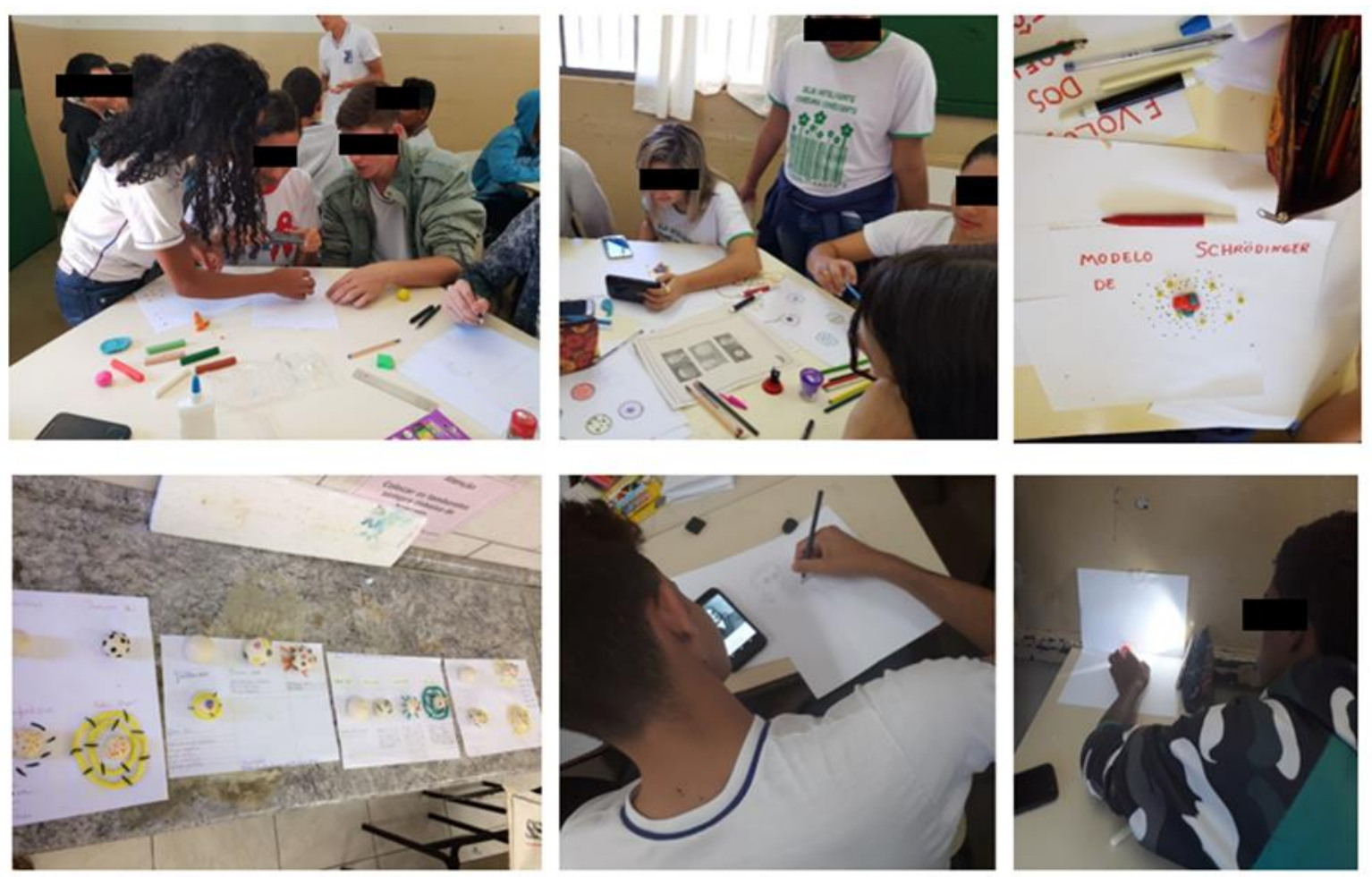

Figura 2: Encontros para preparação dos vídeos de animação.

Observou-se que a participação dos estudantes nesses encontros foi reduzida por terem sido desenvolvidos fora do horário de aula. Alguns discentes não participaram da ação, pois exerciam alguma atividade remunerada no contra turno das aulas presenciais, alcançando uma presença efetiva de 24 estudantes, que correspondeu a $57 \%$ de participação.

Ao longo de 30 dias, foram realizados 5 encontros presenciais que permitiram: i) apresentação da técnica cinematográfica Stop Motion; ii) Realização da oficina; iii) Construção das animações e iv) Socialização dos vídeos. O resultado desses encontros foi a produção de 6 micrometragens de animação com duração média de 60 segundos cada. Os grupos apresentaram os vídeos em sala de aula, através de uma interação divertida e prazerosa, abordando o conteúdo "Evolução dos modelos atômicos" de forma contextualizada e, posteriormente, foram compartilhados entre os estudantes através do aplicativo WhatsApp.

A aplicação dos questionários (Quadro 1) contou com a participação de 24 estudantes e os resultados estão explicitados na Figura 3. 

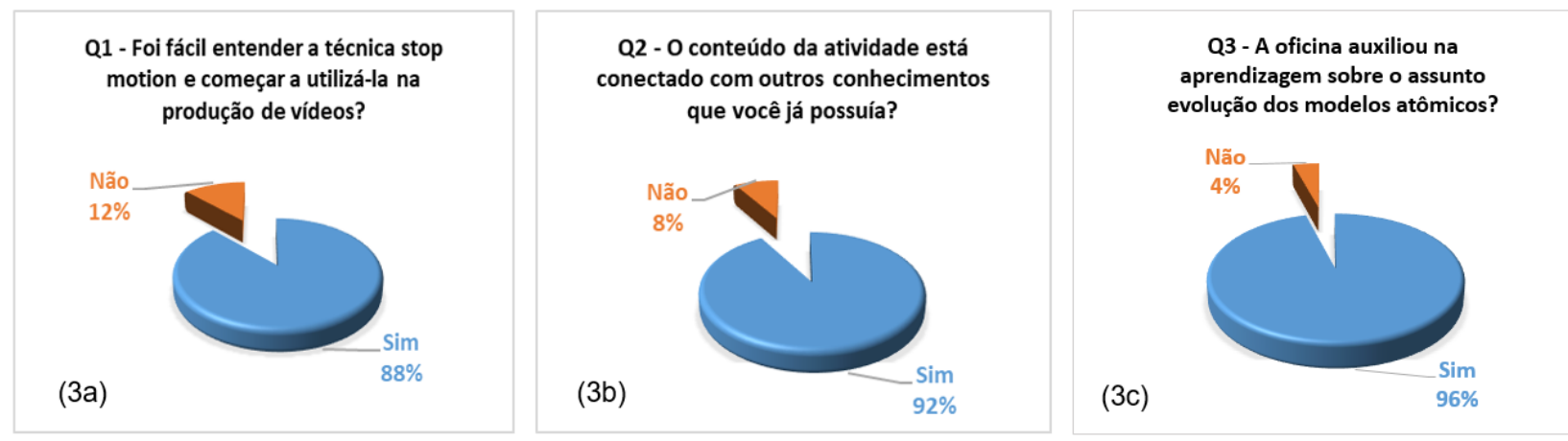

Figura 3: Prancha com gráficos gerados a partir da avaliação quantitativa dos discentes.

Na primeira questão, sobre a facilidade de entender a técnica Stop Motion e aplicá-la na produção de vídeos, $88 \%$ dos discentes não encontraram dificuldade, considerando-a de fácil assimilação (Figura 3a). Entretanto na apresentação dos vídeos em aula foi unânime o reconhecimento por parte dos alunos que a construção da animação demandou envolvimento de todos os participantes em um trabalho artesanal laborioso. Através dessa observação, iniciou-se a discussão sobre o respeito entre os colegas, com destaque para o valor da atividade desempenhada por cada componente do grupo, levando-os a reflexão do grau de dificuldade individual vivenciado pelos membros do grupo para obtenção do resultado final.

Quando questionados se o conteúdo da atividade estava conectado com outros conhecimentos que já possuíam e quais seriam, 92\% responderam que sim (Figura 3b), citando: (i) Familiaridade com o programa Movie Maker; (ii) Utilização de aplicativos de edição de imagens e elaboração de "memes" em celulares (smartphones); (iii) Assistiu filme de animação com a abordagem Stop Motion e (iv) Realizaram o estudo recente do conteúdo de modelos atômicos na disciplina de química. Observou-se que os alunos estão inseridos em letramentos variados (digital, virtual, sonoro, etc.) e familiarizados a diferentes tipos de linguagens. Nesse sentido, Lorenzi e Pádua (2012) complementam o relato quando descrevem que as tecnologias digitais introduzem novos modos de comunicação, como a criação e o uso de imagens, de sons, de animação e a combinação dessas modalidades.

$\mathrm{Na}$ terceira e última questão foi interrogado se a atividade proposta auxiliou na aprendizagem sobre o conteúdo evolução dos modelos atômicos e por quê? Dentre os respondentes, $96 \%$ afirmaram que sim, conforme ilustra a figura 3c, entretanto poucos alunos dissertaram como a atividade desenvolvida, favoreceu o processo ensino-aprendizagem. Dentre as respostas destacou-se as falas: "Permitiu entender melhor o assunto, pois para poder visualizar e estruturar a atividades teve que procurar e estudar mais sobre o assunto"; "O divertido foi ter algo fora da teoria e em grupo, que nos fez buscar mais sobre o assunto para desenvolver a atividade".

Ambas as colocações corroboram a contribuição positiva da atividade proposta na melhoria na relação ensino-aprendizagem, gerando no estudante a vontade de transcender na busca do conhecimento, fazendo o discente adquirir a competência de entender e contextualizar conceitos antes irreais ou abstratos como elétrons, átomos, orbitais e modelos atômicos além de expressar os sentimentos e observações sobre a ciência por meio do imaginário e da arte. O uso dos recursos 
da técnica Stop Motion proporcionou aos alunos uma nova forma de reprodução do conhecimento no ambiente escolar, tornando o ensino de química mais atraente e motivador.

\section{CONCLUSÃO}

Os resultados alcançados permitiram analisar e refletir sobre a proposta complementar e a aplicação do recurso didático de preparo de vídeos sobre conceitos de ciências pelos alunos da rede pública de ensino, para posteriormente em outra fase deste projeto disponibilizar em um canal de educação na internet.

As TICs permitem inovações valiosas para os processos de ensino-aprendizagem através da produção, pelos alunos, de vídeos de curta duração, que permitem a síntese de conceitos, com a efetivação de uma importante ferramenta no processo de construção do conhecimento e consequente aplicação em suas formas práticas.

Destaca-se que a experiência descrita neste trabalho foi significativa, não somente no desenvolvimento de conteúdos trabalhados na disciplina de química, mas também auxiliou no direcionamento de atividades interdisciplinares, impactando de forma positiva nas discussões e nos debates em sala de aula.

\section{REFERÊNCIAS}

Brasil. (2008). Orientações Educacionais Complementares aos Parâmetros Curriculares Nacionais $(P C N+)$. Ciências da Natureza, Matemática e suas tecnologias. Brasília: MEC. Recuperado de http://portal.mec.gov.br/seb/arquivos/pdf/CienciasNatureza.pdf

Costa, M. C., \& Souza, M. A. S. (2017). O uso das TICs no processo ensino e aprendizagem na Escola Alternativa "Lago dos Cisnes". Revista Valore, 2(2), 220-235. https://doi.org/10.22408/reva22201770220-235

Comazzetto, L. R., Vasconcellos, S. J. L., Perrone, C. M., \& Gonçalves, J. (2016). A Geração Y no Mercado de Trabalho: um Estudo Comparativo entre Gerações. Psicologia: ciência e profissão, 36(1), 145-157. https://doi.org/10.1590/1982-3703001352014.

Lorenzi, G. C. C., \& Pádua, T. R. W. (2012). Blog nos anos iniciais do fundamental I. In R. Rojo \& E. Moura. (Org.) Multiletramentos na escola. São Paulo: Parábola Editorial.

Marangoni, A. C., Araujo-Junior, C. F., Conti, C. L. T. M., Silva, H. J.,\& Yamada, M. C. (2017). Flipped Clasroom, um estudo de caso: A produção de vídeos de demonstrações experimentais de física pelos alunos do curso de Engenharia Mecatrônica. In Congresso Internacional ABED de Educação $\quad$ a $\quad$ distância. $\quad$ Recuperado de http://www.abed.org.br/congresso2017/trabalhos/pdf/176.pdf

Martins, G., Galego, L. G. C., \& Araujo, C. H. M. (2017). Análise da produção de vídeos didáticos de Biologia Celular em Stop Motion com base na Teoria Cognitiva de Aprendizagem Multimídia. 
Revista Brasileira de Ensino de Ciência e Tecnologia, 10(3), 185-205. https://doi.org/10.3895/rbect.v10n3.5060

Martins, J. V. G., Menezes, R. M. T, Terçariol, A. A. L, Gitahy, R. R. C; \& Ikeshoji, E. A. B. (2018). The use of mobile in the college classroom: Pedagogy of projects and mobile Technologies in higher education. Revista Ibero-Americana de Estudos em Educação, 13(1), 506-526. https://doi.org/10.21723/riaee.nesp1.v13.2018.10047

Melo, M. G. A., Campos, J. S., \& Almeida, W. S. (2015). Dificuldades enfrentadas por Professores de Ciências para ensinar Física no Ensino Fundamental. Revista Brasileira de Ensino de Ciências e Tecnologia, 8(4), 241-251. https://doi.org/10.3895/rbect.v8n4.2780

Meneses, F. M. G., Nuñes, I. B. (2018). Erros e dificuldades de aprendizagem de estudantes do ensino médio na interpretação da reação química como um sistema complexo. Ciência \& Educação, 4 (1), 175-190. https://doi.org/10.1590/1516-731320180010012

Nicola, J. A., \& Paniz, C. M. (2016). A importância da utilização de diferentes recursos didáticos no ensino de ciências e biologia. InFor - Inovação e Formação - Revista do Núcleo de Educação a Distância da Unesp, 2(1), 355-381. Recuperado de https://ojs.ead.unesp.br/index.php/nead/article/view/InFor2120167/pdf

Paula, J. P., Paula, J. L.; \& Henrique, A. L. S. (2017). O uso do Stop-Motion como prática pedagógica no ensino de geografia no contexto do EMI. Holos, 3, 141-149. https://doi.org/10.15628/holos.2017.5774

Paz, G. L., Pacheco, H. F., Costa-Neto, C. O., \& Carvalho, R. C. P. S. (2010). Dificuldades no ensinoaprendizagem de química no ensino médio em algumas escolas públicas da região sudeste de Teresina. In X Simpósio de produção Científica e IX Seminário de Produção Científica, 2010. Recuperado de http://www.uespi.br/prop/siteantigo/XSIMPOSIO/iniciacao/CCN.html

Reis, I. A., Nascimento, G. S. V., Guimarães, D. M.; Bezerra, G. L. S., Nascimento, S. B. M., Alencar, I. C. C., \& Amado, M. V. (2013). O ensino de Biologia sob uma perspectiva CTSA: análise de uma proposta pedagógica de uso de modelos didáticos da divisão celular. In Atas do IX Encontro Nacional de Pesquisa em Educação em Ciências - IX ENPEC (p. 1-8). Águas de Lindóia, SP, Brasil. Recuperado de abrapec/ixenpec/atas/resumos/R1593-1.pdf

Rodrigues, A. C. L. (2019). Uso das tecnologias na escola: Stop Motion como ferramenta de ensino e aprendizagem. Revista de Educação Popular, 18 (2), 252-269. https://doi.org/10.14393/REPv18n22019-46856

Rodrigues, E. V., \& Lavino, D. (2020). Modelagem no ensino de Física via produção de Stop Motion, com o computador Raspberry Pi. Revista Brasileira de Ensino de Física, 42, e20190012. https://doi.org/10.1590/1806-9126-rbef-2019-0012

Santos, J. W. R., Fonseca, A. C. A. B., Silva, D. L. R., Lucas, F. E., Cardos, G. C. S.; Silva, M. R., Benassi, V. M.; \& Amaral, H. F. (2015). Bio Quiz: Um jogo didático no auxílio da aprendizagem na disciplina de biologia celular no ensino médio. In SBC - Proceedings of SBGames (p. 722-725). 
$\begin{array}{llll}\text { Terezina, } & \text { Bl, } & \text { Recusil. }\end{array}$ http://www.sbgames.org/sbgames2015/anaispdf/artesedesign-short/147887.pdf

Seixas, R. H. M., Calabró, L., \& Sousa, D. O. (2017). A Formação de professores e os desafios de $\begin{array}{lllll}\text { ensinar Ciências. } & \text { Revista } & \text { Thema, } & \text { 14(1), } & \end{array}$ Http://dx.doi.org/10.15536/thema.14.2017.289-303.413

Silva, I. T. (2016). Formação de professores: práticas pedagógicas com Stop Motion. Monografia, UFSC. Santa Catarina. Recuperado de https://repositorio.ufsc.br/xmlui/handle/123456789/168840

Souza, D. M. H., \& Souza, M. (2018). Stop motion: a linguagem cinematográfica e o processo de ensino-aprendizagem através do celular. Divers@! Revista Eletronica Interdisciplinar, 11(2), 114-123. http://dx.doi.org/10.5380/diver.v11i2.62142

Souza, R. V., \& Tolentino-Neto, L. C. B. (2018). O uso das TIC o ensino de Ciências: aplicações tradicionais ou ferramentas cognitivas?. In M. M. A. Souza, \& P. R. C. Nóbrega. (Orgs.). Compartilhando saberes: um panorama sobre a produção acadêmica em múltiplas abordagens teórico-metodológicas (pp. 87-98). Curitiba: CRV.

\section{COMO CITAR ESTE ARTIGO:}

CORRÊA, T. A., MARTINS, H. L., MILLAN, R. N., MARANGONI, A. C. (2020). Uma experiência didática através da ferramenta Stop Motion para o ensino de modelos atômicos. Holos, 36 (6), 1-11.

\section{SOBRE OS AUTORES}

\section{T. A. CORRÊA,}

Departamento de Ciências Exatas e da Terra - Química. E-mail: tais.correa@uemg.br.

ORCID ID: https://orcid.org/0000-0001-9936-1479

\section{H. L. MARTINS}

E-mail: heytor.martins@uemg.br.

ORCID ID: https://orcid.org/0000-0002-5786-2678

\section{R. N. MILLAN}

Departamento de Ciências Exatas e da Terra - Ciências Biológicas. E-mail: rodrigo.millan@uemg.br. ORCID ID: https://orcid.org/0000-0002-9324-7330

\section{A. C. MARANGONI}

Doutor em Engenharia Química pela Universidade Federal do Rio Grande do Norte/UFRN em co-tutela com a Université de Toulon (França); Engenheiro do Instituto Federal de Educação, Ciência e Tecnologia do Rio Grande do Norte/IFRN (Brasil); Membro do Núcleo de Inovação Tecnológica do IFRN. E-mail: antonio.marangoni@uemg.br.

ORCID ID: https://orcid.org/0000-0001-9463-9830

Editor(a) Responsável: Francinaide de Lima Silva Nascimento 
Pareceristas Ad Hoc: MÁRCIA CRISTIANE ELOI SILVA ATAIDE E MICHELE ASLEY LIMA

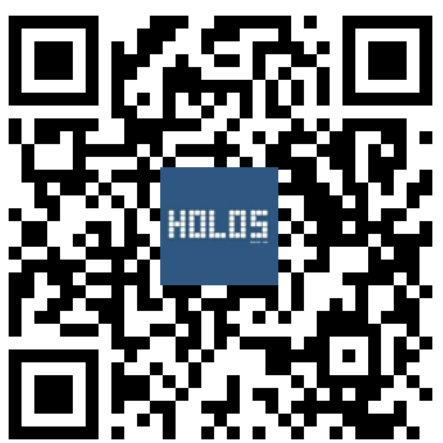

